\title{
ESTUDO DO PRÉ-TRATAMENTO ÁCIDO DA PALHA DE MILHO PARA OBTENÇÃO DE ETANOL DE SEGUNDA GERAÇÃO
}

\author{
M. S. R. SANTOS ${ }^{1}$, W. R. O. PIMENTEL ${ }^{2}$, M. C. S. SILVA², R. M. R. G. ALMEIDA², A. J. G. \\ CRUZ $^{1}$ \\ ${ }^{1}$ Programa de Pós Graduação em Engenharia Química - PPGEQ/UFSCar \\ ${ }^{2}$ Departamento de Engenharia Química - UFAL \\ E-mail para contato: soumaisengquim@gmail.com
}

\begin{abstract}
RESUMO - Nos dias atuais é evidente a necessidade de fontes energéticas renováveis visto que os combustíveis derivados do petróleo são fontes esgotáveis. A biomassa lignocelulósica é fonte promissora, pois possui alto teor de celulose, que pode ser convertida à bioetanol. O grande entrave dessa conversão é sua difícil estrutura, que necessita da realização de um pré-tratamento para melhorar a digestibilidade desse material. Este estudo avaliou o pré-tratamento ácido, através de planejamento experimental em estrela com três fatores da palha de milho. Os fatores estudados foram: tempo, temperatura e concentração de $\mathrm{H}_{2} \mathrm{SO}_{4}$ e as respostas, acidez e ART. Os ensaios foram realizados em autoclave. As melhores condições foram: $120^{\circ} \mathrm{C}, 15 \mathrm{~min}$ e $0,5 \%$ de $\mathrm{H}_{2} \mathrm{SO}_{4}$, onde obteve-se $50,9 \%$ de ART e à $110^{\circ} \mathrm{C}, 7$ min e $2 \%$ de ácido, com $59,4 \%$ de ART. Para essas condições, realizou-se hidrólise enzimática e fermentação. A maior eficiência fermentativa foi dada na condição à $120^{\circ} \mathrm{C}, 15 \mathrm{~min}$ e $0,5 \%$ de $\mathrm{H}_{2} \mathrm{SO}_{4}$ : 92,9\%.
\end{abstract}

\section{INTRODUÇÃO}

A crescente preocupação com o desenvolvimento sustentável vem dando ênfase a busca por fontes alternativas de energia, fazendo com que a utilização de combustíveis fósseis seja reduzida (CHEN, et. al., 2006). Dentro desse contexto, os resíduos lignocelulósicos estão em posição de destaque, uma vez que possuem alto teor de material que pode ser convertido a etanol (DAGNINO, et. al., 2012). A palha de milho, que é um resíduo normalmente desperdiçado no campo, têm se mostrado como alternativa promissora para a produção de etanol 2G (GEORGIEVA; AHRING, 2007). A maior dificuldade apresentada por esse tipo de biomassa é sua estrutura rígida, que apresenta como componentes principais celulose, hemicelulose e lignina (ROGALINSKI, et. al., 2008). A celulose, que é o polímero de interesse, encontra-se na estrutura envolvida pela hemicelulose e lignina, dificultando seu acesso, tornando necessária a realização de um pré-tratamento, que terá como objetivo principal, alterar a estrutura dessa biomassa, tornando os açúcares passíveis à fermentação (PIENKOS; ZHANG, 2009). Nessa etapa, vários processos têm sido propostos e desenvolvidos, incluindo-se os físicos, químicos e biológicos. O pré-tratamento com ácido sulfúrico pode alcançar elevadas taxas de reação e, com isso atingir o objetivo de melhorar a hidrólise da celulose (SUN; CHENG, 2002). O processo de obtenção do etanol a partir da biomassa lignocelulósica envolve a etapa de hidrólise dos polissacarídeos, expostos após etapa de pré- 


\section{9 a 22 de outubro de 2014 \\ Florianópolis/SC}

tratamento, em açúcares de cadeias menores que são fermentescíveis. Um processo de hidrólise enzimática com prévia etapa de pré- tratamento pode ter o seu rendimento aumentado de $20 \%$ para 90\%, o que faz com que o pré-tratamento seja etapa decisiva na produção do etanol (NOJIRI, 2009). A fermentação alcoólica ocorre por uma série de reações, que são catalisadas por um complexo de enzimas, presentes no metabolismo de diferentes microrganismos, sendo o mais utilizado a levedura Saccharomyces cerevisae (SZCZODRAK e FIEDUREK, 1996). Esse trabalho apresenta um estudo do pré-tratamento ácido da palha de milho, por um planejamento fatorial em estrela com três fatores (tempo, temperatura e concentração de $\mathrm{H}_{2} \mathrm{SO}_{4}$ ), em que o teor de açúcares redutores totais (ART) e de acidez foram as respostas obtidas. A escolha dos níveis de cada fator foi devido a limitações dos equipamentos ou baseados na literatura. Após o pré-tratamento foram realizadas as etapas de hidrólise com a enzima Acellerase 1500 e a fermentação etanólica com fermento comercial.

\section{MATERIAIS E MÉTODOS}

\subsection{Materiais}

A palha de milho in natura foi oriunda de espigas compradas na feira livre da cidade de Maceió-AL. O extrato enzimático (Accelerase 1500) foi gentilmente cedido pela UFSCar, através de projeto de cooperação. Na etapa de fermentação foi utilizada a levedura Saccharomyces cerevisiae (na forma liofilizada da marca Fermix). Os demais reagentes de laboratório foram adquiridos em grau analítico e não sofreram qualquer tratamento antes de sua utilização.

\subsection{Métodos}

Higienização, secagem e trituração das palhas: As palhas sofreram processo de sanitização, que consistiu em lavagem com 100 ppm de água sanitária por 15 minutos. Após esse tempo, foram lavadas em água corrente. Em seguida, as palhas passaram por secagem em estufa (à $45^{\circ} \mathrm{C}$ ). Após se apresentar com aspecto quebradiço foi triturada em um moinho de facas tipo Willye.

Determinação do teor de umidade: A umidade da biomassa foi medida empregando-se um determinador de umidade modelo ID50 (Marte Balanças e Aparelhos de Precisão Ltda) a $100^{\circ} \mathrm{C}$ em modo automático.

Pré-tratamento com ácido sulfúrico: Um planejamento experimental com três fatores, em estrela e triplicata no ponto central foi realizado, com o objetivo de otimizar o pré-tratamento. Os três fatores estudados foram: tempo, temperatura e $\left[\mathrm{H}_{2} \mathrm{SO}_{4}\right]$. Os pontos em estrela estão a uma distância de $\sqrt{2}$ unidades codificadas do ponto central. As respostas avaliadas foram acidez e ART, onde as duas melhores condições, em termos de ART obtido, foram escolhidas para seguir às etapas de hidrólise enzimática e fermentação. A metodologia do pré-tratamento ácido é descrita a seguir: a massa seca de material foi pesada em balança analítica de acordo com o teor de umidade; A razão foi de 1:10 (m/v), como proposto por SILVA et al. (2010); As soluções de ácido sulfúrico foram preparadas de acordo com a concentração requerida; A massa do material foi adicionada ao Erlenmeyer e em seguida o volume da solução de ácido; Os Erlenmeyers foram tampados e colocados na autoclave; Após o tempo de experimento, as amostras foram retiradas da autoclave e filtradas; O teor de ART e a acidez 
foram determinados do licor obtido desse pré-tratamento.

Determinação dos açúcares redutores totais (ART) e acidez: A determinação dos açúcares redutores totais (ART) foi feita pelo método espectrofotométrico, proposto por Miller (1959), que utiliza a solução de ácido 3,5-dinitrosalicílico (DNS) e leitura a $540 \mathrm{~nm}$. A acidez foi determinada conforme metodologia do Instituto Adolf Lutz (1985).

Hidrólise enzimática: Os ensaios submetidos à hidrólise enzimática foram realizados com a fração sólida do material pré-tratado, utilizando a enzima comercial Accellerase 1500. Os ensaios ocorreram segundo Silva (2011), com 1,0\% de carga de sólidos. A solução para hidrólise continha $60 \mathrm{~mL}$ de tampão citrato, pH 4,8 (50 mM), $38 \mathrm{~mL}$ de água destilada e $2 \mathrm{~mL}$ da enzima. A hidrólise enzimática ocorreu em frascos Erlenmeyer de $250 \mathrm{~mL}$ em Shaker, à $50^{\circ} \mathrm{C}$ e $150 \mathrm{rpm}$, por 72 horas. Após a hidrólise enzimática, o ART foi determinado.

Fermentação do hidrolisado enzimático: Foi utilizada a levedura Saccharomyces cerevisiae comercial. Os ensaios ocorreram de acordo com Wolf (2011), onde o líquido contendo glicose resultante da hidrólise enzimática foi utilizado na fermentação. Para o preparo do inóculo, foi utilizado o meio de cultura YPD. Em frascos Erlenmeyer de $250 \mathrm{~mL}$ foram adicionados: $30 \mathrm{~mL}$ do hidrolisado, 0,6 $\mathrm{g}$ de peptona bacteriológica e $0,3 \mathrm{~g}$ de extrato de levedura. $\mathrm{O}$ meio foi esterilizado à $121^{\circ} \mathrm{C}$ por 15 min. Após isso, foi adicionada $6,7 \mathrm{~mL}$ da solução de sulfato de magnésio e fosfato de amônio e $0,3 \mathrm{~g}$ do fermento. A fermentação ocorreu em Shaker à $30^{\circ} \mathrm{C}, 200 \mathrm{rpm}$ por 24 horas. O teor alcoólico foi determinado por destilação, utilizando-se o método espectrofotométrico a partir do dicromato de potássio. $\mathrm{O}$ rendimento da fermentação $\left(\mathrm{R}_{\mathrm{f}}\right)$ foi calculado pela relação entre o etanol produzido e o ART presente inicialmente. A eficiência da fermentação foi determinada pela relação entre o rendimento real da fermentação e o teórico de 0,51 (NOGUEIRA; VENTURINI-FILHO, 2005).

\section{RESULTADOS E DISCUSSÃO}

\subsection{Matriz de Planejamento do Pré-tratamento Ácido}

A Tabela 1 apresenta todas as condições do pré-tratamento ácido, de acordo com o planejamento em estrela com triplicata no ponto central e as respostas obtidas. O teor de ART da biomassa in natura foi de: $17,88 \%$.

Tabela 1 - Matriz de planejamento: Resultados para a palha de milho

\begin{tabular}{|c|c|c|c|c|c|}
\hline Ensaio & $\begin{array}{c}\text { Fator 1 } \\
\text { (tempo) }\end{array}$ & $\begin{array}{c}\text { Fator 2 } \\
\text { (temperatura) }\end{array}$ & $\begin{array}{c}\text { Fator 3 } \\
\text { (concentração } \\
\left.\mathrm{H}_{2} \mathrm{SO}_{4}\right)\end{array}$ & ART (\%) & Acidez (\%) \\
\hline 1 & $15(-)$ & $100(-)$ & $0,5(-)$ & 18,8 & 0,6 \\
\hline 2 & $120(+)$ & $100(-)$ & $0,5(-)$ & 45,4 & 0,7 \\
\hline 3 & $15(-)$ & $120(+)$ & $0,5(-)$ & 50,9 & 0,6 \\
\hline 4 & $120(+)$ & $120(+)$ & $0,5(-)$ & 42,7 & 0,7 \\
\hline
\end{tabular}




\begin{tabular}{|c|c|c|c|c|c|}
\hline 5 & $15(-)$ & $100(-)$ & $3,5(+)$ & 33,6 & 3,0 \\
\hline 6 & $120(+)$ & $100(-)$ & $3,5(+)$ & 25,5 & 2,0 \\
\hline 7 & $15(-)$ & $120(+)$ & $3,5(+)$ & 33,4 & 3,1 \\
\hline 8 & $120(+)$ & $120(+)$ & $3,5(+)$ & 32,4 & 1,6 \\
\hline 9 & $67,5(0)$ & $110(0)$ & $2(0)$ & $37,5 \pm 0,3$ & $1,0 \pm 0,1$ \\
\hline 10 & $67,5(0)$ & $110(0)$ & $2(0)$ & $38,6 \pm 0,3$ & $1,1 \pm 0,1$ \\
\hline 11 & $67,5(0)$ & $110(0)$ & $2(0)$ & $37,7 \pm 0,3$ & $0,9 \pm 0,1$ \\
\hline 12 & $7(-\sqrt{ } 2)$ & $110(0)$ & $2(0)$ & 59,4 & 1,6 \\
\hline 13 & $142(+\sqrt{ } 2)$ & $110(0)$ & $2(0)$ & 31,7 & 1,4 \\
\hline 14 & $67,5(0)$ & $96(-\sqrt{ } 2)$ & $2(0)$ & 14,8 & 1,2 \\
\hline 15 & $67,5(0)$ & $124(+\sqrt{ } 2)$ & $2(0)$ & 7,3 & 1,5 \\
\hline 16 & $67,5(0)$ & $110(0)$ & $0,1(-\sqrt{ } 2)$ & 17,1 & 0,2 \\
\hline 17 & $67,5(0)$ & $110(0)$ & $4(+\sqrt{ } 2)$ & 32,5 & 3,6 \\
\hline
\end{tabular}

Pela Tabela 1, verifica-se que as duas condições de maiores percentuais de ART foram a 3, com $50,9 \%$ de ART e $0,6 \%$ de acidez e a 12 , com 59,4\% de ART e 1,6\% de acidez, seguindo portanto para as etapas de hidrólise e fermentação.

\subsection{Análise de Variância - Modelo Estatístico}

Para verificar se o modelo estatístico obtido é adequado ao sistema que se quer descrever, é necessário adequá-lo a um modelo empírico que possa reproduzir com confiança os dados experimentais. Para isso constrói-se a tabela ANOVA - análise de variância. Nesse trabalho, o ajuste mais adequado se deu por um modelo cúbico (BRUNS, et. al., 2001). As Tabelas 2 e 3 mostram os resultados da ANOVA para cada resposta do planejamento experimental. Observa-se que para ambos os casos, o modelo cúbico se adequou satisfatoriamente, visto que o percentual de variação explicada esteve sempre bem próximo ao explicável pelo modelo. As superfícies de resposta dos modelos cúbicos também são apresentadas nas Figuras 1 e 2, considerando o nível inferior do tempo.

Tabela 2 - ANOVA para o modelo cúbico: ART palha

\begin{tabular}{|c|c|c|c|}
\hline Fonte de Variação & Soma quadrática & $\begin{array}{c}\mathbf{N}^{\circ} \text { de graus } \\
\text { de liberdade }\end{array}$ & $\begin{array}{c}\text { Média } \\
\text { quadrática }\end{array}$ \\
\hline Regressão & 2748,30 & 13 & 211,41 \\
\hline Resíduo & 92,35 & 3 & 30,78 \\
\hline Falta de Ajuste & 91,60 & 1 & 91,60 \\
\hline Erro Puro & 0,75 & 2 & 0,37 \\
\hline Total & 2840,65 & 16 & \\
\hline \% de variação explicada: 96,75; \% de variação explicável: 99,97 \\
\hline
\end{tabular}




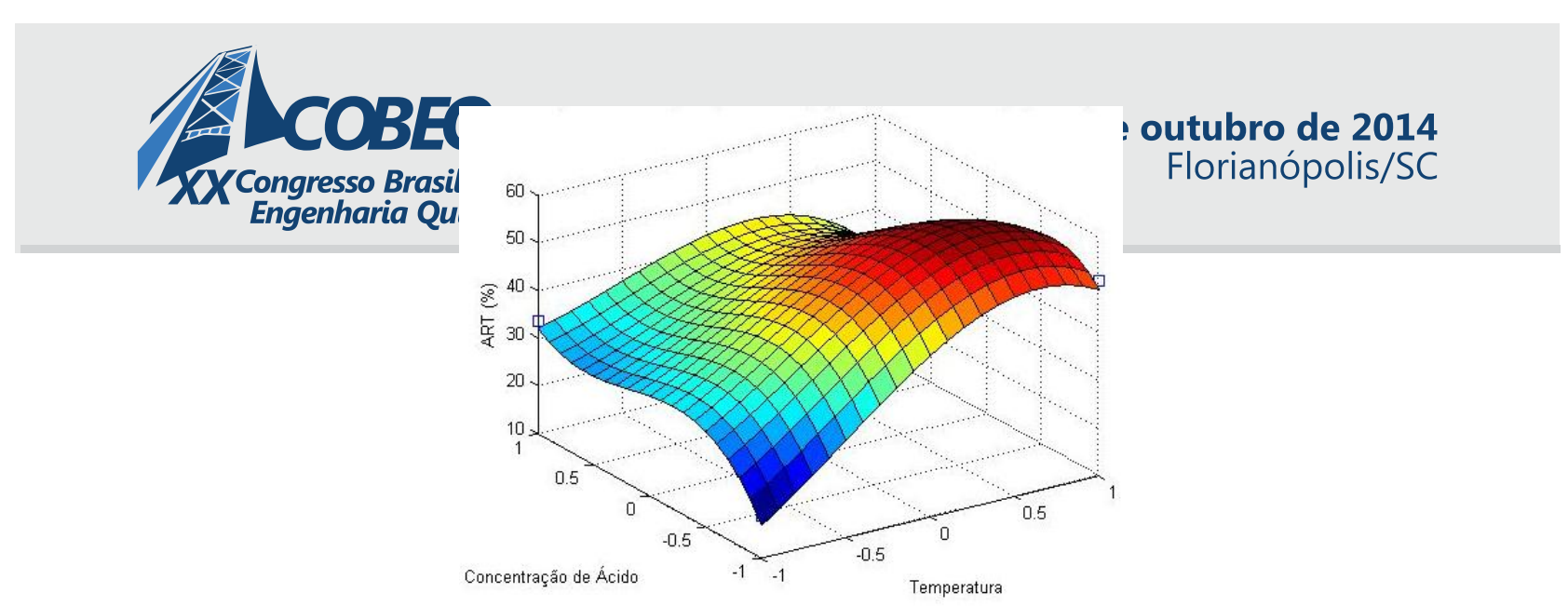

Figura 1 - Superfícies de resposta em 3 dimensões para o ART da palha no nível inferior de tempo.

Pela Figura 1, maiores percentuais de ART são obtidos ao utilizar baixas concentrações de $\mathrm{H}_{2} \mathrm{SO}_{4} \mathrm{e}$ altas temperaturas. A análise estatística dos fatores mostra que neste caso, a concentração de ácido reduz em média $4,11 \%$ do teor de ART quando se passa do nível inferior para o superior desse fator. Indicando que para trabalhar com maiores valores de ART (\%) deve-se utilizar concentrações de $\mathrm{H}_{2} \mathrm{SO}_{4}$ na faixa de $0,5 \%$. Já o efeito da temperatura, que se mostrou o mais significativo dos três, indicou que um aumento médio de $4,50 \%$ no ART é obtido quando eleva-se a temperatura de 100 para $120^{\circ} \mathrm{C}$. O tempo foi o que apresentou menor efeito no sistema. No entanto, o seu efeito combinado com a temperatura e/ou com a concentração de $\mathrm{H}_{2} \mathrm{SO}_{4}$ indica que se deve trabalhar com menores valores de tempo para se obter maiores percentuais de ART. Por uma análise química e estrutural da biomassa, em relação ao ácido, esse fato é facilmente entendido, visto que sua presença, em concentrações elevadas, pode acarretar na formação de produtos inibidores, que são responsáveis pela degradação do material lignocelulósico, e consequentemente dos açúcares presentes na estrutura (ALMEIDA, et. al., 2007). Já para o caso da temperatura, a faixa investigada não foi ampla, de 100 a $124^{\circ} \mathrm{C}$, por conta de restrições do equipamento, $\operatorname{logo}$ é muito provável que não se tenha atingido uma temperatura de degradação, onde há perdas de massa. Portanto, não houve problemas ao se trabalhar no nível superior de temperatura, onde ocorrerá uma maior desorganização na estrutura lignocelulósica, tornando os açúcares fermentescíveis mais acessíveis, gerando maiores concentrações de ART após pré-tratamento (DAGNINO, et. al., 2012).

Tabela 3 - ANOVA para o modelo cúbico: Acidez palha

\begin{tabular}{|c|c|c|c|}
\hline Fonte de Variação & Soma quadrática & $\begin{array}{c}\mathbf{N}^{\circ} \text { de graus } \\
\text { de liberdade }\end{array}$ & $\begin{array}{c}\text { Média } \\
\text { quadrática }\end{array}$ \\
\hline Regressão & 15,12 & 13 & 1,16 \\
\hline Resíduo & 0,15 & 3 & 0,05 \\
\hline Falta de Ajuste & 0,13 & 1 & 0,13 \\
\hline Erro Puro & 0,02 & 2 & 0,01 \\
\hline Total & 15,26 & 16 & \\
\hline \% de variação explicada: 99,04; \% de variação explicável: 99,88 \\
\hline
\end{tabular}




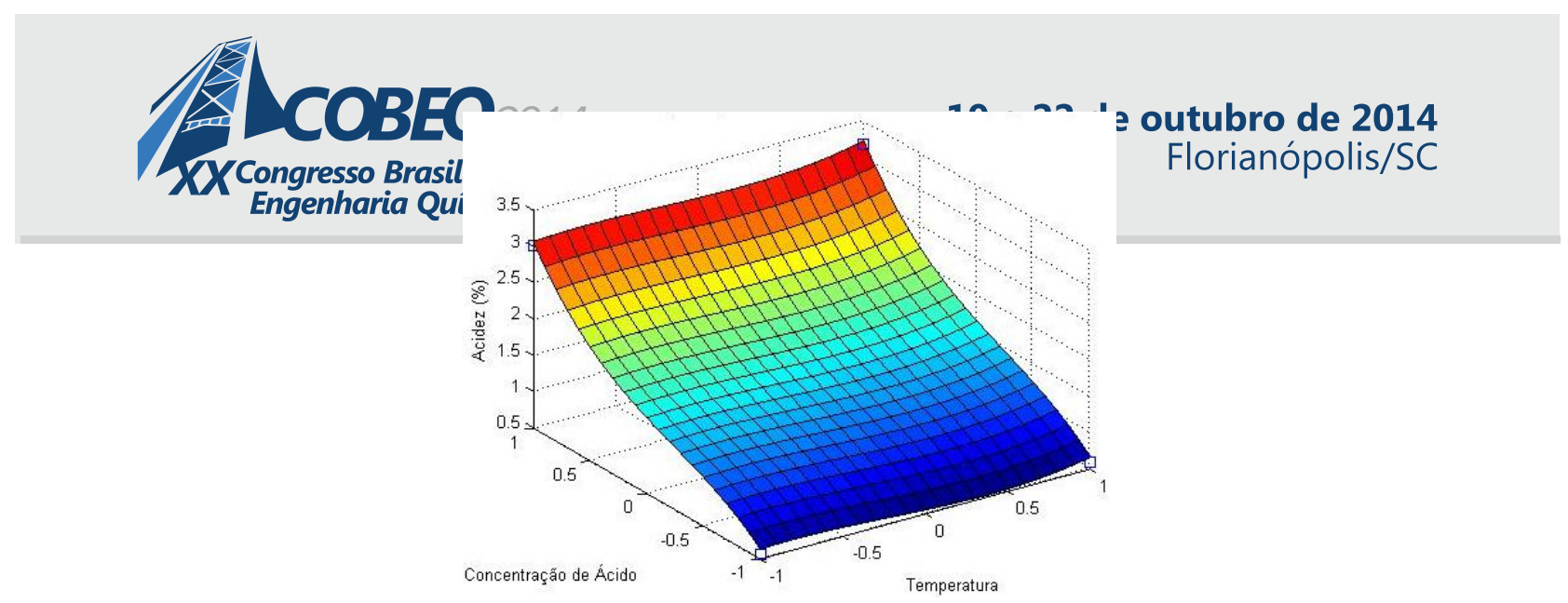

Figura 2 - Superfícies de resposta em 3 dimensões para a Acidez da palha no nível inferior de tempo.

Pela Figura 2, os menores índices de acidez, ideal para um bom pré-tratamento, são identificados em baixas concentrações de ácido, porém são independentes da temperatura. É fato indiscutível que quanto maior a concentração de ácido, maior será o teor final de acidez. Com a análise estatística nota-se que, na faixa investigada, a temperatura não mostrou ser um fator significativo na resposta da acidez, nem mesmo sua interação com os outros fatores. A concentração de ácido foi o mais significativo dos três fatores nas condições estudadas. A interação da concentração do ácido com o tempo foi a que se mostrou mais significativa, e o efeito de interação mostra que o menor tempo aliado as menores concentrações de ácido fornecem os menores percentuais de acidez. Com a análise conjunta, para maiores valores de ART e menores de Acidez, deve-se utilizar temperatura em torno de $120^{\circ} \mathrm{C}$, tempo de $15 \mathrm{~min}$ e $\left[\mathrm{H}_{2} \mathrm{SO}_{4}\right]$ em torno de $0,5 \%$.

\subsection{Etapas de Hidrólise Enzimática e Fermentação}

A Tabela 4 mostra os resultados de ART após as etapas de hidrólise enzimática e fermentação.

Tabela 4 - Resultados obtidos após as etapas de hidrólise enzimática e fermentação

\begin{tabular}{|c|c|c|c|c|c|}
\hline $\begin{array}{c}\text { Condição do } \\
\text { Planejamento }\end{array}$ & $\begin{array}{c}\text { Concentração } \\
\text { de ART no } \\
\text { hidrolisado } \\
(\mathrm{g} / \mathrm{L})\end{array}$ & $\begin{array}{c}\text { Conversão } \\
\text { Enzimática } \\
(\%)\end{array}$ & $\begin{array}{c}\text { Etanol } \\
\text { Produzido } \\
(\mathrm{g} / \mathrm{L})\end{array}$ & $\begin{array}{c}\text { Rendimento } \\
\text { da } \\
\text { Fermentação } \\
(\%)\end{array}$ & $\begin{array}{c}\text { Eficiência } \\
\text { da } \\
(\%)\end{array}$ \\
\hline $\begin{array}{c}3\left(15 \mathrm{~min} ; 120^{\circ} \mathrm{C} ;\right. \\
\left.0,5 \% \text { de } \mathrm{H}_{2} \mathrm{SO}_{4}\right)\end{array}$ & 19,6 & 83,3 & 9,3 & 47,4 & 92,9 \\
\hline $\begin{array}{c}12\left(7 \mathrm{~min} ; 110^{\circ} \mathrm{C} ;\right. \\
\left.2 \% \text { de } \mathrm{H}_{2} \mathrm{SO}_{4}\right)\end{array}$ & 10,4 & 59,0 & 4,4 & 42,3 & 82,9 \\
\hline
\end{tabular}

Pode-se perceber que a maior eficiência fermentativa se deu na condição 3 do pré-tratamento ácido (15 min; $120^{\circ} \mathrm{C}$ e $0,5 \% \mathrm{H}_{2} \mathrm{SO}_{4}$ ), onde se obteve o maior teor de etanol: 9,3 g/L. Essa condição foi a que apresentou o menor teor de acidez, viabilizando em consequência, maior produção de etanol. A condição 12 por sua vez, apresentou menor teor de etanol. Nessa condição do planejamento experimental uma maior concentração de ácido foi utilizada, o que pode ter causado inibição nas etapas posteriores, acarretando em menor teor de etanol produzido devido a maior concentração de 
compostos tóxicos. Para o acompanhamento da fermentação o crescimento celular foi avaliado, conforme Figura 3.

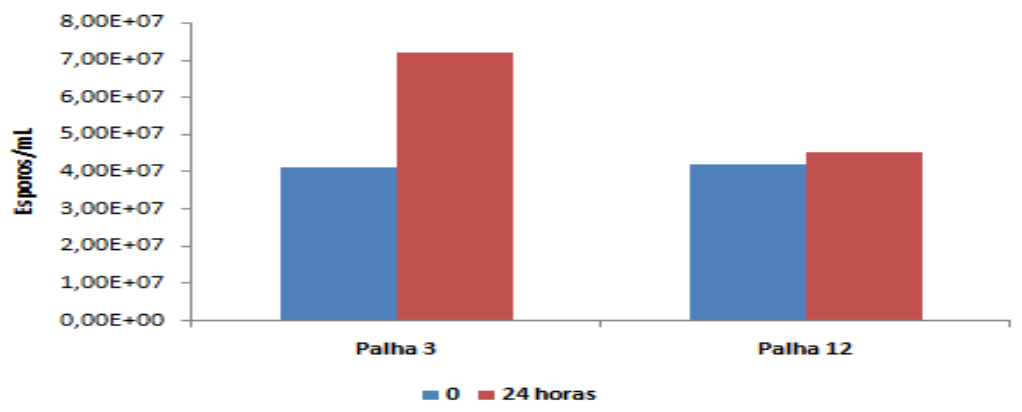

Figura 3 - Crescimento celular após 24 horas de fermentação.

Verifica-se na Figura 3 que as condições fermentativas estiveram favoráveis ao desenvolvimento do microrganismo, onde após as 24 horas de fermentação houve crescimento celular. Esse crescimento foi mais acentuado para a palha de milho na condição 3 do pré-tratamento.

\section{CONCLUSÕES}

O planejamento experimental foi uma ferramenta que permitiu avaliar as melhores condições estudadas e assim otimizar as etapas subsequentes. Os maiores índices de ART e baixos teores de acidez foram dados ao se utilizar altas temperaturas e baixas concentrações de ácido, na faixa investigada. Também na faixa estudada, o fator tempo não se apresentou como significativo. A palha apresentou melhores rendimentos em ART nas condições de: $15 \mathrm{~min}, 120{ }^{\circ} \mathrm{C}$ e $0,5 \%$ de $\mathrm{H}_{2} \mathrm{SO}_{4}$. A acidez, nessa condição apresentou valores baixos; outra condição de bons resultados em ART foi com $7 \mathrm{~min}, 110{ }^{\circ} \mathrm{C}$ e $2 \%$ de $\mathrm{H}_{2} \mathrm{SO}_{4}$, porém nessa condição, o teor de acidez foi mais acentuado. Nas etapas de hidrólise e fermentação, obteve-se melhor resultado com a condição 3 do pré-tratamento: $15 \mathrm{~min}, 120{ }^{\circ} \mathrm{C}$ e $0,5 \%$ de $\mathrm{H}_{2} \mathrm{SO}_{4}$, onde obteve-se a maior eficiência de fermentação.

\section{AGRADECIMENTOS}

A CAPES - Coordenação de Aperfeiçoamento de Pessoal de nível Superior - e ao CNPq Conselho Nacional de Desenvolvimento Científico e Tecnológico - pelo apoio financeiro. Ao projeto “casadinho”/PROCAD, CNPq/ CAPES (n06/2011), uma cooperação entre a UFAL, UFSCar e UFRJ.

\section{REFERÊNCIAS}

ALMEIDA, J. R. M; MODIG, T.; PETERSSON, A; HÄHN-HÄGERDAL, B.; LIDÉN, G.; GORWA-GRAUSLUND, M. F. Increased tolerance and conversion of inhibitors in lignocellulosic hydrolysates by Saccharomyces cerevisiae. J. of Chem. Technol. \& Biotechnol., v. 82 , n. 4, p. 340-349, 2007; 


\section{9 a 22 de outubro de 2014 \\ Florianópolis/SC}

BRUNS, R. E.; NETO, B. B.; SCARMÍNIO, I. S. Como fazer experimentos. Pesquisa e desenvolvimento na ciência e na indústria, $2^{a}$ edição, Editora Unicamp, 2001;

CHEN, M.; XIA, L.; XUE, P. Enzymatic hydrolysis of corncob and ethanol production from cellulosic hydrolysate. International Biodeterioration and Biodegradation, Elsevier. 59 (2007) 85-89, 2006;

DAGNINO, E .P.; CHAMORRO, E. R.; ROMANO, S. D.; FELISSIA, F. E.; AREA, M. C. Optimization of the acid pretreatment of rice hulls to obtain fermentable sugars for bioethanol production. Industrial Crops and Products, Elsevier. p.363-368, 2012;

GEORGIEVA, T. I.; AHRING, B. K. Evaluation of continuous ethanol fermentation of dilute-acid corn stover hydrolysate using thermophilic anaerobic bacterium Thermoanaerobacter BG1L1. Applied Microbiol. and Biotechnol., Springer. 77:61-68, 2007;

INSTITUTO ADOLF LUTZ (IAL). Métodos Químicos para Análise de Alimentos. 3 ed. São Paulo, 1985;

MILLER, G. L. Use of dinitrosalicylic acid reagent for determination of reducing sugar. Analytical Chemistry, v.31, p. 426-428, 1959;

NOGUEIRA, A. M. P.; VENTURINI-FILHO, W. G. Aguardente de cana. Botucatu: UNESP/Faculdade de Ciências Agronômicas, 2005. Disponível em: <http://dgta.fca.unesp.br/docentes/waldemar/aguardente/Aguardente.pdf >. Acesso em: $27 \mathrm{de}$ janeiro de 2014;

NOJIRI, N. Jpn. Kokai Tokkyo Koho JP2009159904-A 2009. (CA 151:175883);

PIENKOS, P. T.; ZHANG, M. Role of pretreatment and conditioning processes on toxicity of lignocellulosic biomass hydrolysates. Cellulose, Springer. 16:743-762, 2009;

ROGALINSKI, T.; INGRAM, T.; BRUNNER, G. Hydrolysis of lignocellulosic biomass in water under elevated temperatures and pressures. J. of Supercritical Fluids, 47 (2008) 54-63, 2008;

SILVA, A. P.; RAVAGNANI, M. A. S. S.; BISCAIA Jr., E. C.; CABALlERO, J. A. Optimal heat exchanger network synthesis using particle swarm optimization. Optimization and Engineering (Print), v. 11, p. 459-470, 2010;

SILVA, G. M. Pré-tratamento do bagaço de cana de açúcar com amônia aquosa para a produção de etanol. Dissertação de mestrado, UFSCar, São Carlos - São Paulo, 2011;

SUN, Y.; CHENG, J. Hydrolysis of lignocellulosic materials for ethanol production: a review. Bioresour. Technol., 83:1-11, 2002;

SZCZODRAK, J.; FIEDUREK, J. Technology for conversion of lignocellulosic biomass to ethanol. Biomass and Bioenergy, 10(5/6):367-375, 1996;

WOLF, L. D. Pré-tratamento organossolve do bagaço de cana-deaçúcar para a produção de etanol e obtenção de xilooligômeros. 148 p. Dissertação de mestrado - Departamento de Engenharia Química, Universidade Federal de São Carlos, São Carlos, 2011. 